\title{
The specifics of investment resources management in the enterprise
}

\section{O. B. Pankov}

Kiev Polytechnic Institute named after Igor Sikorsky, Kiev, Ukraine

Corresponding author. E-mail: pankov25@ukr.net

Paper received 29.08.19; Accepted for publication 14.09.19.

\author{
https://doi.org/10.31174/SEND-HS2019-205VII34-07
}

\begin{abstract}
The investment activity is one of the most important factors of sustainable growth and dynamic development of Ukrainian economy, as far as it forms the basis for reproduction and expansion of production and innovation potential of domestic enterprises, increasing their competitiveness and efficiency of functioning. The study of the effectiveness of the investment process, its impact on the socio-economic sustainability of the enterprise is an urgent task for the enterprise management and effective development. The paper investigates and analyzes the approaches to the essence of the concept of enterprise investment resources management and outlines its main features and characteristics. The paper defines the essence, purpose and tasks of enterprise investment resources management and its influence on the formation of effective functioning of the enterprise. The continuous search for the new approaches to manage the enterprises investment resources enterprises ensure their profitability and increase the level of economic development.
\end{abstract}

Keywords: investment, investment activity, of investment resources management, domestic enterprise.

Introduction. Within the framework of the development of a market economy, investment activity is considered as the main factor of sustainable growth and economic development. The use of investment resources in the work of the company forms the basis for the reproduction and expansion of their production and innovation potential, increasing their competitiveness.

However, the lack of an integral high-performance investment management system that is adequate to the requirements of a changing market environment and aimed at the ensuring of investment resources rational use. The actualization of the problem of improving and developing scientific methodical approaches and tools for managing investment activities, the application of which will contribute to accelerating the socio-economic development of Ukrainian enterprises by investing capital.

Analysis of recent researches and publications. Today, the research of the enterprise investment resources management was carried out by such leading Ukrainian scholars as I. Blank, A. Galchinsky, V. Heyets, N. Gerasimchuk, A. Goyko, V. Grinyova, B. Gubsky, V. Zaruba, O. Kuzmin, Yu. Makogon, P. Break, A. Peresada, M. Chumachenko, A. Yakovlev, O. Yastremskaya and others. Among foreign scientists it is possible to distinguish the following scientists: V. Berens, G. Burman, V. Bocharov, M. Bromwich, L. Guitman, L. Krushwitz, V. Mertens, V. Shapiro, W. Sharp, V. Sheremet and others.

The purpose of the article is to determine the essence of the concept of resources investment management of the enterprise and to distinguish its main features and characteristics.

The tasks of the paper are:

to study and characterize of managing investment resources of an enterprise and to identify its features.

to define the features of the enterprise investment resources management.

The object of the research is the process of enterprise investment resources managing.

Results. Effective activity of any enterprise is in efficient without a well-organized and well-established management system. The company is stable and liquid thanks to the effective management of investment activity, it is enable the receiving of profit while covering all its expenses. An acute problem is the effective management of investment (investing) of capital in order to increase it and to the current transitional period, with the variety of complex economic crisis processes and the relationship between enterprises, financial institutions, and states in the domestic and foreign markets. The economic nature of investment is determined by the laws of the process of expanded reproduction, in consists of the part usage of an additional social product. That increases the quantity and quality of all elements of the system of productive forces of society. Investments in the broad sense can be defined as the cost of resources that are carried out in order to obtain future profit or profit. In this section, the decision to invest is different from the decisions aimed at consumption, which is characterized by the receipt of only immediate utility $[1,146]$.

The purpose of activity investment management is: reflection of the future state of the economy due to the volume of investments in production; - ensuring the required profitability and urgency of achieving the goals; development of investment strategy; - analysis of the economic situation of the enterprise and expediency of attraction of investments; - identify the weak and strong sides of the enterprise; - definition of ways of development of an enterprise engaged in a certain type of activity characteristic of him, etc. [2, 85]

Investment management is a complex, multilevel process that involves managerial decisions not only at the level of business entities - investors and investment participants, but also at the state and regional level. Today, it is possible to distinguish three levels of management of investment activities of the enterprise.

The first level is a macro level. At this level, certain regulatory measures are taken to ensure the investment activity of the enterprise. In other words, management is at the regional level.

The second level is called the macro level. At this level, the management of investment activity at the enterprise level is carried out.

Different levels of management meet different goals. In particular, the purpose of management is favorable conditions for the investment activity of various entities in the respective territory (state or specific region). At the macro level, the main goal is to maximize the efficiency of the investment activity of an individual enterprise. At the same time, we can state the relationship between these management objectives. After all, regulation of investment activity at the state and regional levels is an external factor that determines the effectiveness of investment 
activity at the level of a specific entity. Subject to the achievement of the objectives of investment management at the micro level, the preconditions for achieving the desired effect of macroeconomic regulation are created.

In general, the enterprise management process combines the implementation of four successive stages:

1) the implementation of specific management functions through the general management functions;

2) the formation of management methods as ways of influencing the control subsystem of the enterprise to the managed;

3) formalization of management methods in managerial decisions on alternative grounds;

4) ensuring the influence of the management system of the enterprise on the guiding principles of management.

Consequently, enterprise management is a set of purposeful influences of the company's management personnel aimed at achieving a certain goal, on improving the functioning of the object of management, that is, on ensuring its development. Management of investment activity should be considered as part of the overall system of enterprise management. It is necessary to pay attention to the following features of enterprise management:

1. integration with the general enterprise management system

2. complexity in the process of forming managerial decisions on the implementation of investments in relation to the final results of the financial activity of the enterprise

3. high level of management dynamism in the field of formation and realization of investments

4. multivariate approaches to the adoption of individual management decisions in the sphere of formation of investment resources of the enterprise

5. orientation to the strategic development of the enterprise

The purpose of investment activity management is to reflect the future state of the economy due to the volume of investments in production; ensuring the necessary profitability and urgency of achieving goals; development of investment strategy; analysis of the economic situation of the enterprise and expediency of attraction of investments; definition of ways of development of an enterprise engaged in a certain type of activity characteristic of him; identify the weak and strong sides of the enterprise, etc. [2, p. 85].

The process of managing the investment activity of an enterprise includes the following tasks:

- research of the external investment environment and forecasting of the future conjuncture of the investment market;

- development of strategic directions of investment activity of the enterprise;

- search and evaluation of investment attractiveness of individual projects and selection of the most effective ones;

- development of strategy of formation of investment resources of the enterprise; assessment of investment qualities of individual financial instruments and selection of the most effective ones;

- formation of an investment portfolio and its estimation on indicators of profitability, liquidity and risk;

- current planning and operational management of the implementation of individual investment projects;

- organization of monitoring of the implementation of individual investment programs and projects;

- preparation of decisions on timely exit from ineffective investment projects [3].

The basis of the investment activity of the enterprise is to provide the most effective ways to expand the assets of the company from the perspective of its development prospects and increase its market value.

In view of this, the content of the investment activity of the enterprise is part of the overall financial strategy. It consists in choosing and implementing the most effective ways to expand the volume of assets of the enterprise to ensure the main directions of its developmentю.

Management of investment activity should be considered as part of the general system of enterprise management.

Many factors influence the enterprise management system. One of these factors is the integration with the general system of enterprise management, the complexity in the process of forming managerial decisions regarding the implementation of investments in relation to the final results of the financial activity of the enterprise, the high level of management dynamism in the field of formation and implementation of investments, the multivariate approach to the adoption of individual management decisions in the sphere of formation of investment resources of the enterprise, orientation on the strategic development of the enterprise.

In our opinion, the main objective of managing the investment activity of an enterprise is to obtain maximum profit not only in the current, but also in perspective periods. This involves solving a number of issues, in particular: developing an investment strategy of the enterprise; search and formation of investment resources; evaluation of project effectiveness; formation and evaluation of the investment portfolio; assessment of the investment attractiveness of the enterprise. Based on the above, it can be concluded that the investment management system of the enterprise is part of the overall system of enterprise management and includes the development of the activities of the enterprise in the part of the investment, aimed at increasing profit, due to long-term investments of capital intended for the creation, placement, reconstruction, modernization, technical re-equipment of the enterprise. Regulation of the process of development and implementation of investment decisions of the enterprise can be carried out by means of the appropriate mechanism, which includes the following elements: market mechanism of regulation of investment activity of the enterprise, state regulatory legal regulation, system of methods of investment activity management and internal regulation of its separate aspects.

The effectiveness of the management system will be achieved by improving investment activity in its main parts: organizational security, information security, planning, monitoring, monitoring of investment projects, financial and economic calculations, performance evaluation.

Organizational support includes an interconnected set of business units that provide development and decisionmaking on investment activity management and are fully responsible for implementing these decisions. We believe that a significant effect of investment activity is achieved only if there is an effective information management system for investment activities that can be presented in the form of information indicators that are necessary for 
analysis, planning, management decision making, etc. Such a system, in our opinion, should meet the needs of both external and internal users. An important component of the strategic development of the investment activity of the enterprise is the planning, the main purpose of which is to develop plans to ensure the development of the company with the necessary investment resources and increase the efficiency of this kind of activity in the future. Planning investment activity of any enterprise begins after solving the question of whether it is worth investing in this project, that is, whether a positive cash flow will be sufficient for the reimbursement of expenses and the receipt of certain profit.

An important place in the system of management of investment activity of the enterprise belongs to the control, the basic principles of construction of which are:

- focus on the implementation of the investment strategy;

- orientation towards standards;

- conformity of control methods to methods of analysis and planning;

- the timeliness of the control allows to eliminate the current deviations before they can take a serious charac- ter;

- flexibility and ease of construction;

Conclusions. The profitability implies the equality of expenditures on the size of the effect that can be achieved in the process of its implementation.

The main purpose of investments in the enterprise is to provide various forms of long-term development of the enterprise and the accumulation of its capital. The concept of investment activity of the enterprise should be defined as a set of operations related to the implementation of investment projects to obtain a long-term growth of its market price.

In order to improve the quality of the management of investment activity at enterprises, it is expedient to automate the processes of investment activity. It is also necessary to create an optimal system of operational management of investment activities, which will be formed with subsystems of planning, organization and control of investments. In turn, investments will be controlled by the company's management to ensure effective and stable socio-economic development. Such steps will enable the enterprise to adapt constantly to changing environmental conditions.

\section{REFERENCES}

1. Zamyatina N. Theoretical and methodical principles of management of investment activity of the enterprise / N. Zamyatina // Financial space. - 2013. - No. 3 (11). - C. 138-142.

2. Kerancchuk T. Financial stability of the enterprise and methodical aspects of its assessment / T. Kerancchuk // Econo-

my of Ukraine. - 2000. - No. 1. - P. 83-86.

3. Bondar N. Management of investments in the enterprise / N. Bondar. URL http://businessconsultant.com.ua/publicacim401.html 